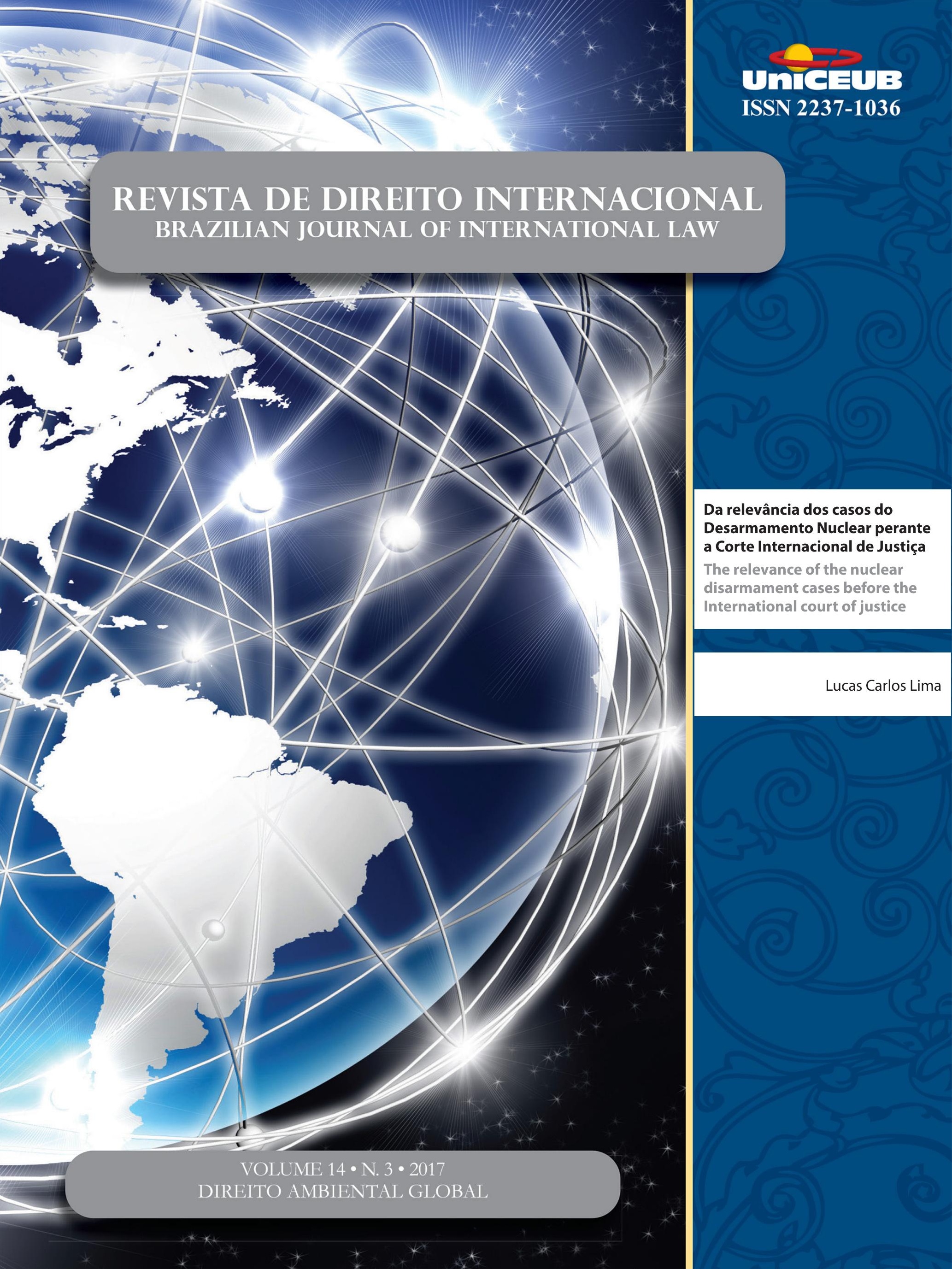




\section{Sumário}

I. Crônicas do Direito Internacional ...............................................1

CRÔNICAS DE DiREITO INTERNACIONAL PÚBLICO ........................................................................ 3

A política australiana de Refúgio e a decisão da Suprema Corte de PAPUA NOVA GUINÉ: A

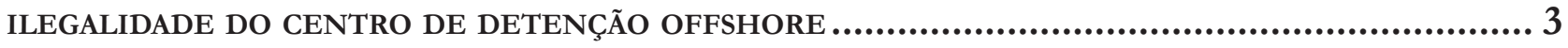

Tarin Cristino Frota Mont'Alverne e Ana Carolina Barbosa Pereira Matos

II. Dossiê especial: Direito Ambiental Global............................................ 7

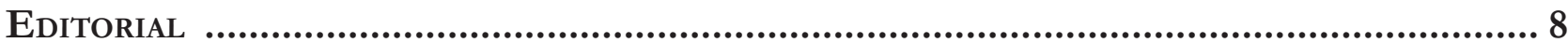

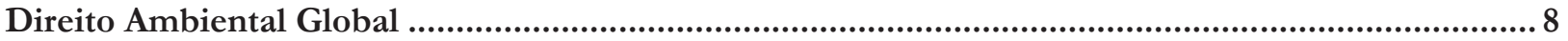

Priscila Pereira de Andrade

Direito Global: UMa TEORIA ADEQUAda PARA SE PENSAR o DiREITO AMBIENTAL? ................10 Arnaud Van Waeyenberge

“Complex is Beautiful": What role for the 2015 Paris Agreement in making the Effective Links within the Climate Regime Complex? .................................................21 Sandrine Maljean-Dubois e Matthieu Wemaëre

UNE ILLUSTRATION DU DROIT GLOBAL, LA LEX MERCATORIA CLIMATIQUE...............................31 Mathilde Hautereau-Boutonnet

OCÉANS ET CHANGEMENTS CLIMATIQUES : RECHERCHER LES INTERACTIONS AU SEIN DE LA FRAGMENTATION DU DROIT INTERNATIONAL

Sophie Gambardella

Une gouvernance globale du Climat par la transparence depuis l'Accord de Paris: Le DROIT GLOBAL DE L'ENVIRONNEMENT COMME SOLFÈGE? .56

Anne-Sofie Tabau 
LA PROGRESSIVE HARMONISATION DES RÈGLES DU PROCÈS ENVIRONNEMENTAL: MANIFESTATION

DE L'ÉMERGENCE D'UN DROIT GLOBAL? ............................................................69

Eve Truilhé-Marengo

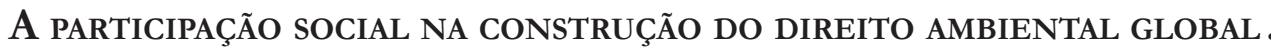
80 Michelle Lucas Cardoso Balbino

A PROTEÇÃo AMBIENTAL COMO EFEITO INDIRETO DO SISTEMA DE GESTÃo DE ENERGIA ISO 50001

Matheus Linck Bassani e Ricardo Serrano Osorio

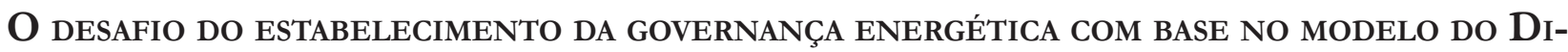
reito Administrativo Global: ESTUdo de CASO DAS ENERgias RENOVÁveis. 122 Alice Rocha da Silva

Othon Pantoja Oliveira de Azevedo

O PRINCÍPIO DA PARTICIPAÇÃo E A CRIAÇÃO E GESTÃo DAS ÁREAS PROTEGIDAS NA PERSPECTIVA DO DIREITO AMBIENTAL GLOBAI

Marcia Dieguez Leuzinger e Solange Teles da Silva

A teoria Ambientalista (GREen theOry) e a COMpetênCia CONSUltiva da CoRTE InTERAmericana de Direitos Humanos: O caso da Colômbia................................................. 148

Eduardo Biacchi Gomes e Ane Elise Brandalise

III. Artigos sobre outros temas....................................................... 160

30 anos do Protocolo de Montreal: Uma história de sucesso do Direito Ambiental

INTERNACIONAL 162

Fernando Rei e Valeria Cristina Farias

MinORIAS NACIONAIS, PROTEÇão INTERNACIONAL E TRANSNACIONALIDADE 182 Ana Maria D'Ávila Lopes e Luis Haroldo Pereira dos Santos Junior

Da relevância dos casos do Desarmamento Nuclear perante a Corte Internacional DE JUSTIÇA 203 Lucas Carlos Lima 
OS CONTROLES DE CONVENCIONALIDADE TRADICIONAL E INTERAMERICANO: INSTITUTOS DISTINTOS OU DUAS FACES DA MESMA MOEDA?

Gilberto Schäfer, Roger Raupp Rios, Paulo Gilberto Cogo Leivas e Jesus Tupã Silveira Gomes

EL SOFT LAW COMO FUENTE DEL DERECHO INTERNACIONAL: REFLEXIONES DESDE LA TEORÍA DE LA COMPLEJIDAD

Rafael Sanz e André Folloni

Ley de rotulación de alimentos de Chile: ¿'Traba comercial o protección de la saLUD?

Nicolás Cobo

IV. RESENHA DE LIVRO.

O CiVILIZAdor gentil das AmÉRICAS: CONSIDERAÇÕes EM TORNO DA OBRA THE HIDDEN HIStory of International LaW in the Americas: Empire and LeGal Networks, de Juan Pablo SCARFI 278

Cicero Krupp da Luz

'Mestizo International Law: A global intelectual history 1842 - 1933' De Autoría de Arnulf Becker-Lorca .283 Jimena Sierra-Camargo

América Latina em Continuidades e rupturas 287 Adriane Sanctis 


\title{
Da relevância dos casos do Desarmamento Nuclear perante a Corte Internacional de Justiça*
}

\author{
The relevance of the nuclear disarmament \\ cases before the International court of \\ justice
}

Lucas Carlos Lima**

\section{Resumo}

Este trabalho visa determinar se a decisão da Corte Internacional de Justiça sobre as objeções preliminares nos casos do Desarmamento Nuclear oferece outras contribuições além da questão da existência de uma controvérsia. A tese geral sustentada é que essas contribuições existem e são, pelo menos, três. Por primeiro, o fato de que a Corte revisitou e reafirmou alguns princípios básicos relativos a armas nucleares. Em segundo lugar, argumenta-se que o julgamento serviu, igualmente, para dar reconhecimento à causa nuclear da República das Ilhas Marshall e para reconhecer "o sofrimento que seu povo suportou”. Por fim, algumas questões processuais serão examinadas, principalmente aquelas não resolvidas pela Corte como a questão do princípio do Ouro Monetário e a ausência de um efeito prático do julgamento. Essas questões permanecem em aberto, embora tenham sido objeto de análise de alguns juízes em suas opiniões individuais. Ao tratar desses três pontos, conclui-se que o julgamento oferece elementos de reflexão que vão além da questão do que é uma controvérsia e contribui, em pelo menos três aspectos distintos, para o debate jurídico internacional.

Palavras-chave: nuclear, desarmamento, Corte Internacional de Justiça

* Recebido em 13/11/2017

Aprovado em 18/12/2017

** Professor Adjunto de Direito Internacional na Universidade Federal de Minas Gerais. Doutor em Direito Internacional pela Universidade de Macerata (Itália). Participou da Equipe de Defesa das Ilhas Marshall perante a Corte Internacional de Justiça. As opiniões vinculadas neste artigo espelham tão somente as opiniões do autor. E-mail: lucaslima00@hotmail.com

\section{Abstract}

This essay aims at determining whether the decisions on preliminary objections by the International Court of Justice on the cases Cessation of the $\mathrm{Nu}$ clear Arms Race and to Nuclear Disarmament offers other contributions beyond the question of the existence of a dispute. The general thesis sustained is that these contributions exist and they are at least three. Firstly, the fact that the Court has revisited and reaffirmed some basic principles regarding nuclear weapons. Secondly, it is argued that the judgment has equally served to give recognition to the nuclear cause of the Republic of Marshall Islands and to acknowledge "the suffering which its people endured". Ultimately, some procedural questions shall be examined, particularly those not solved by the Court such as the issue of the Monetary Gold principle and the absence of practical consequences of the judgment. These questions remained 
open, though they were the object of analysis of some judges in their individual opinions. By elaborating on these three points, it will be concluded that the outcome of the judgments offers food for thought beyond the question of what is a dispute and contributes, in at least three different aspects, to the international legal debate.

Keywords: nuclear, disarmament, International Court of Justice

\section{INTRODUÇÃO.}

Em suas decisões do dia 5 de outubro de 2016, a Corte Internacional de Justiça (CIJ ou Corte), principal órgão judiciário da Organização das Nações Unidas (ONU), encerrou, preliminarmente, o litígio trazido pela República das Ilhas Marshall contra o Reino Unido, Índia e Paquistão ${ }^{1}$. Tratava-se de controvérsia em que o Estado composto por conjunto de ilhas do pacífico, severamente abaladas por 67 testes nucleares durante os anos 1940 e 1950, invocava o Tratado de Não Proliferação de Armas Nucleares (TNP) e as respectivas obrigações consuetudinárias para arguir que os Estados reclamados não estavam cumprindo suas obrigações de negociar o desarmamento nuclear. Por meio de uma votação que cindiu a Corte, a razão pela qual o caso não prosseguiu ao mérito foi o entendimento da maioria dos juízes pela ausência de uma controvérsia entre as partes - requisito fundamental para que a Corte da Haia possa exercer sua jurisdição ${ }^{2}$.

1 CORTE INTERNACIONAL DE JUSTIÇA. Obligations concerning Negotiations relating to Cessation of the Nuclear Arms Race and to Nuclear Disarmament (Marshall Islands v. United Kingdom); Obligations concerning Negotiations relating to Cessation of the Nuclear Arms Race and to Nuclear Disarmament (Marshall Islands v. India); Obligations concerning Negotiations relating to Cessation of the Nuclear Arms Race and to Nuclear Disarmament (Marshall Islands v. Pakistan). Julgamento sobre Objeções Preliminares. 5 de Outubro de 2016. [Caso do Desarmamento Nuclear]. Para uma descrição geral do caso, ver GRAY, Christine. "The 2016 Activity of the International Court of Justice", American Journal of International Law, Vol. 111, pp. 415-436, 2017.

2 Por uma questão de precisão, nota-se que a votação da Corte foi, nos casos das Ilhas Marshall contra Paquistão e Índia, de divisão de 9 a 7. No caso das Ilhas Marshall contra o Reino Unido, a divisão foi de 8 a 8, com o Presidente da Corte sendo o casting vote decisório, nos termos do artigo 55 (2) do Estatuto da Corte. A razão para tal diferenciação entre os casos foi o entendimento do juiz Yusuf de que no caso contra o Reino Unido, a disputa entre as partes cristalizara-se durante os procedimentos. Sobre a questão, ver Caso do Desarmamento Nuclear, nota supra 1 Reino Unido, Decisão Dissidente Juiz Yusuf, paras 6-15.
O não prosseguimento do caso, sobretudo por se tratar de dois tópicos sensíveis como o desarmamento e uso de armas nucleares, gerou repercussões e críticas à saída formalista adotada pela maioria da Corte, seja no interior da Corte ${ }^{3}$, seja por seus comentadores ${ }^{4}$. Contudo, uma indagação que parece não ter recebido ampla atenção é se a decisão preliminar da CIJ possui relevância em outros aspectos. A tese geral sustentada neste trabalho é de que outros elementos relevantes existem e merecem reflexão.

Foi precisamente observado por comentadores que os casos do Desarmamento Nuclear são particularmente importante por uma série de motivos. 1. Trata-se da quinta decisão da CIJ em relação a armas nucleares e a segunda vez que, diretamente, Estados resolvem litigar a questão por iniciativa individual 5 ; 2 . É a primeira vez, na jurisprudência da Corte, que se utiliza o argumento da não existência de uma controvérsia para recusar o caso em via preliminar; 3. Poucas vezes na história da Corte, os juízes se dividiram de tal maneira a exigir que o Presi-

3 As opiniões dissidentes dos juízes Bennouna, Cançado Trindade, Robinson e Crawford e do juiz ad hoc Bedjaoui e dos juízes são eloquentes nesse sentido.

4 KRISCH, Nico. "Capitulation in The Hague: The Marshall Islands Cases", Post no EJIL: Talk!, 10 de Outubro de 2016. Disponível em <https://www.ejiltalk.org/capitulation-in-the-haguethe-marshall-islands-cases/>. BONAFÈ, Beatrice Ilaria. "La Cour internationale de Justice et la notion de différent" Ordine internazionale e diritti umani, Vol. 5, pp. 924-933, 2016.VENZKE, Ingo. "Public interests in the International Court of Justice - a comparison between Nuclear Arms Race (2016) and South West Africa (1966)" AJIL Unbound, Vol. 111, pp.68-74. BIANCHI, Andrea. "Choice and (the awareness of) its consequences: the ICJ's "structural bias" strikes again in the Marshall Islands case" AJIL Unbound, Vol. 111, pp. 81-87, 2017. ANGHIE, Anthony. "Politic, Cautious, and the meticulous: an introduction to the symposium on the Marshall Islands case" AJIL Unbound, Vol. 111, pp. 62-67, 2017. GALINDO, George Rodrigo Bandeira. "On form, substance and equality between States" AJIL Unbound, Vol. 111, pp. 75-80. STOPPIONI, Edoardo. "The ICJ Decisions In The Marshall Islands Cases Or The Unintended Consequences Of "Awareness", post no SIDIBlog, 24 de novembro de 2016. Disponível em http:/ / www.sidiblog. org/2016/11/24/the-icj-decisions-in-the-marshall-islands-cases-orthe-unintended-consequences-of-awareness/).

5 Referidas decisões foram CORTE INTERNACIONAL DE JUSTIÇA. Nuclear Tests (Australia v. France). ICJ Reports 1974. p. 253; CORTE INTERNACIONAL DE JUSTIÇA. Nuclear Testes (New Zealand v. France). ICJ Reports 1974. p. 457; CORTE INTERNACIONAL DE JUSTIÇA. Legality of the Use by a State of Nuclear Weapons in Armed Conflict. Opinião Consultiva. ICj Reports 1996. p. 66; CORTE INTERNACIONAL DE JUSTIÇA. Legality of the Threat or Use of Nuclear Weapons. Opinião Consultiva. ICJ Reports 1996. p. 226 [Parecer Legality of the Threat]. Sobre a questão, ver RANGANATHAN, Surabhi. "Nuclear Weapons and the Court" AJIL Unbound, Vol. 111, pp. 88-95, 2017. 
dente utilizasse seu voto de minerva. 4. Existe um certo e bem delineado simbolismo em relação ao fato de que um ex-Presidente da Corte (juiz ad hoc Bedjaoui), que deu o voto de minerva no parecer anterior sobre armas nucleares $^{6}$, tenha retornado de sua aposentadoria para somar sua voz a dos dissidentes no presente caso; 5 . O caso parece se inserir em um contexto maior relativo a armas nucleares, expresso pelo recém assinado Tratado de Proibição de Armas Nucleares (TPAN). ${ }^{7}$

Embora outros aspectos relevantes possam existir, o presente trabalho examinará três questões. Em primeiro lugar, será analisado o fato de a Corte ter revisitado o regime jurídico relativo a armas nucleares e a maneira como o conduziu em obiter dicta. Em seguida, o foco do trabalho será guiado para as considerações feitas pela Corte acerca da República das Ilhas Marshall. Sustenta-se que parte do julgamento serviu não apenas para dar reconhecimento à legitimidade das Ilhas Marshall em seu ativismo pelo desarmamento nuclear, mas igualmente para reconhecer "o sofrimento suportado pela população" daquele Estado. Por fim, tecem-se considerações de natureza processual, em especial sobre questões não resolvidas pela Corte e que permanecem em aberto dentro do regramento processual da Corte. Embora possam ser considerados de menor impacto do que uma decisão final de mérito, ao elaborar-se sobre esses três pontos, conclui-se que a contribuição dos julgamentos dos casos do Desarmamento Nuclear vai além da crítica quanto ao mero formalismo adotado pela Corte e, em três aspectos diversos, oferece uma contribuição ao debate jurídico internacional.

\section{Do REGIME JURÍDICO INTERNACIONAL SOBRE AS ARMAS NUCLEARES}

Não é raro em casos perante tribunais internacionais uma longa recapitulação dos fatos envolvendo a disputa ou o direito envolvido. É antiga prática da CIJ um detalhado registro das posições sustentadas pelas partes, seguida da manifestação da Corte sobre a questão. Trata-se, obviamente, de registro e tributo à igualdade soberana dos soberanos clientes que, ao aceitarem a jurisdição da Corte, aceitaram participar de um rito jurídico

6 Parecer Legality of the Threat, nota 5 supra, parte dispositiva.

7 Treaty on the Prohibition of Nuclear Weapons. Adotado em 7 de julho de 2017. Ver: https://www.un.org/disarmament/ptnw/ internacional dotado de impacto não apenas em relação ao litígio, mas que o transcende. Como observado por dois autores,

\begin{abstract}
“os pronunciamentos da Corte não são apenas uma maneira para resolver pacificamente controvérsias entre Estados, mas eles também se esforçam para estabelecer um acurado registro histórico, seja através da história da negociação entre dois Estados no contexto de uma delimitação marítima ou disputa fronteiriça, a história da cunhagem de uma particular convenção, ou os fatos que são pano de fundo de um conflito armado relevante para uma controvérsia perante a Corte" (TOMKA, PROULX, 2016, p.1 $)^{8}$.
\end{abstract}

As relações entre justiça e história, justiça e narrativa e a maneira como tribunais e cortes internacionais às vezes responsabilizam-se pela narrativa de um determinado registro ou "verdade" foram objeto de estudo". Uma conclusão que se pode extrair desses estudos é que órgãos jurisdicionais muitas vezes são eloquentes por meio da recapitulação e reafirmação de determinados fatos. Tal exercício é ainda mais relevante quando os fatos reforçados numa determinada controvérsia são normas jurídicas. Este parece ser o caso na controvérsia do Desarmamento Nuclear.

Os parágrafos 18 a 21 da decisão são centrais nesse sentido ${ }^{10}$. Primeiramente, a Corte recapitula os contornos jurídicos e a formação do TNP, relembrando o fato de que conferências de revisão ocorrem a cada cinco anos desde sua entrada em vigor bem como o fato de que 191 Estados se tornaram partes do instrumento. É interessante notar que, mesmo nos julgamentos relativos a Índia e Paquistão - Estados que não são partes do TNP —, a Corte realiza esse exercício. Tal fato poderia sugerir certa inclinação da Corte ao identificar

8 Do original: “the Court's pronouncements are not only a way to peacefully resolve disputes between States, but they also strive to establish an accurate historical record, be it of the negotiation history between two States in the context of a maritime delimitation case or boundary dispute, the drafting history of a particular international convention, or the background facts to an armed conflict relevant to a dispute before the Court".

9 COSTA, Pietro. "Di che cosa fa storia la storia della giustizia? Qualche considerazione di metodo" in L LACCHÈ, Luigi; MECCARELLI, Massimo. (org) Storia della giustizia e storia del diritto (EUM 2007) 17-43. D'ASPREMONT, Jean. The Control Over Knowledge by International Courts and Arbitral Tribunals. In SCHULTZ, Thomas; ORTINO, Federico. (orgs) Oxford Handbook of International Arbitration. Oxford: Oxford University Press. (No prelo); TAMS, Christian J. "World Courts as Guardians of Peace", Global Cooperation Research Paper 15 (2016).

10 Nos julgamentos da Índia e Paquistão, os parágrafos são os de número 17 a 20. 
certas obrigações contidas no TNP como de natureza consuetudinária.

A CIJ prossegue rememorando os objetivos principais do Tratado, bem como reforça que a intenção das partes ao assiná-lo era "conseguir, no menor prazo possível, a cessação da corrida armamentista nuclear e de adotar medidas eficazes tendentes ao desarmamento nuclear" (TNP, Preâmbulo). Em seguida, a Corte aborda o conteúdo do artigo VI do TNP, a base principal da demanda das Ilhas Marshall, o qual prescreve que

\begin{abstract}
"Cada Parte deste Tratado se compromete a entabular, de boa-fé, negociações sobre medidas efetivas para a cessação em data próxima da corrida armamentista nuclear e para o desarmamento nuclear, e sobre um Tratado de desarmamento geral e completo, sob estrito e eficaz controle internacional".
\end{abstract}

No parágrafo 20, a Corte vai além do TNP e invoca a decisão da Opinião Consultiva de 1996 requerida pela Assembleia Geral sobre a legalidade do uso de armas nucleares no direito internacional. Foi citada, diretamente, a passagem em que a Opinião reforçou que a obrigação de negociar em boa-fé o desarmamento nuclear vai além de uma obrigação de conduta e era "uma obrigação de obter um resultado preciso - desarmamento nuclear em todos os seus aspectos - por meio da adoção de um curso de conduta particular, nomeadamente, realizar negociações sobre a questão de boa fé" (CIJ, 1996, para. 99). A Corte ainda reforçou o duplo caráter da obrigação acrescentando que "qualquer busca realista para um geral e completo desarmamento, em especial o desarmamento nuclear, requer a cooperação de todos os Estados" (CIJ, 1996, para. 100). Por fim, a Corte de 2016 corroborou a conclusão da Corte de 1996 invocando a célebre conclusão da parte dispositiva "existe uma obrigação de perseguir em boa fé e de chegar a uma conclusão negociações guiando ao desarmamento nuclear em todos os seus aspectos e sob um controle internacional estrito e efetivo". ${ }^{11}$ Por fim, a CIJ mencionou resoluções da Assembleia Geral em que os Estados reforçaram a existência dessa obrigação.

Quais são as conclusões que podem ser extraídas dessa construção da Corte Internacional de Justiça sobre o direito relativo à obrigação de negociação de armas nucleares? Existem duas considerações que merecem atenção. A primeira é a questão da natureza da obrigação evocada pela Corte. A segunda questão é a influência do direito invocado pela Corte no âmbito do

11 Parecer Legality, nota 5 supra, para 105 (2) F.
Tratado de Proibição de Armas Nucleares (TPAN).

Nota-se que a Corte em 2016 não é explícita ao reconhecer de maneira incontroversa e definitiva a existência de uma obrigação consuetudinária. Diversos elementos apontam nessa direção. Contudo, é relevante que a Corte não tenha se atido tão somente aos dizeres do tratado, mas sim à interpretação posterior dada à obrigação em 1996 que vai além dos dizeres do tratado. Independentemente da natureza, a CIJ em 2016 reforça o duplo caráter da obrigação, seja a obrigação de conduta, mas também obrigação de resultado: entabular de boa-fé negociações $e$ chegar a uma conclusão ("bring to a conclusion") levando ao desarmamento nuclear. É incontroverso o fato de que reforçar uma conclusão da Corte tomada em 1996 em 2016 é reforçar o conteúdo daquela conclusão. Pode-se sustentar que, ao fazê-lo, a Corte reforça a existência da obrigação para além do Tratado de Não Proliferação.

É verdade que a Corte, tal qual o fez em 1996, não explicitou nem teceu maiores elaborações sobre a natureza de tal obrigação. A óbvia dificuldade da caracterização como norma consuetudinária reside na associação com a prática estatal. Tal elemento demonstra-se difícil de ser evidenciado no presente caso por diversos motivos como apenas determinados Estados poderem, efetivamente, realizarem tal negociação. Note-se, porém, que imediatamente em seguida a tal afirmação, a CIJ invoca resoluções da Assembleia Geral em relação à obrigação, forte indicativo de seu caráter consuetudinário. Nesse sentido, vale mencionar a conclusão número 12 do projeto de conclusões da Comissão de Direito Internacional para a identificação do direito consuetudinário que lida, expressamente, com Resoluções de organizações internacionais (OIs). O projeto não somente reconhece que resoluções de OIs são forma de prática e opinio juris, mas também expressa que, em determinadas circunstâncias, uma resolução "pode refletir uma regra costumeira de direito internacional"12. Contudo, embora a decisão de 2016 possa ser interpretada como um discreto indicativo dessa conclusão, não o afirma em definitivo.

Por um lado, pode-se sustentar que a contribuição da decisão da Corte, a título de obiter dictum, para o direito relativo às armas nucleares não foi significativa do ponto de vista de novas contribuições. Por outro lado, pode-se igualmente sustentar que a reafirmação de cer-

12 COMISSÃO DE DIREITO INTERNACIONAL. A/ CN.4/L.872. Art. 12, 3. 
tos princípios básicos relativos a armas nucleares reforça a regra primária reconhecida pela Corte em 1996.

A segunda observação é que parece interessante notar que a construção frasal empregada pela Corte em seu parecer de 1996, reutilizada pelas Ilhas Marshall e pela Corte em 2016 vem repetida ipsis literis no preâmbulo do Tratado de Proibição de Armas Nucleares quando este "reafirma que existe uma obrigação de perseguir em boa fé e de chegar a uma conclusão negociações guiando ao desarmamento nuclear em todos os seus aspectos e sob um controle internacional estrito e efetivo" (TPAN, Preâmbulo) ${ }^{13}$. Em diversas passagens, o TPAN prevê a negociação em direção à total eliminação de armas nucleares, seja por parte de Estados, seja por parte da autoridade a ele atribuída. Tais passagens permitem que se sustente o TPAN privilegia, ainda que, na forma de outras obrigações, a obrigação geral de negociar o desarmamento nuclear.

Outro aspecto do Tratado pode levantar um interrogativo. O Artigo 11, que dispõe sobre os meios de solução de controvérsias em relação à aplicação ou interpretação do Tratado, não prevê nenhum órgão jurisdicional específico para o deslinde de disputas, deixando ampla a escolha do meio pelo qual Estados resolverão controvérsias de acordo com o artigo 33 da Carta. A Corte Internacional de Justiça não ganha nenhum papel de proeminência no Tratado. Não se pode afirmar, com base nas declarações dos países durante as negociações, se a decisão de não colocar a CIJ em proeminência como método de solução de controvérsias possui alguma relação com sua decisão no caso do Desarmamento Nuclear. O TNP sequer possui uma disposição em relação à solução de controvérsias. Independentemente disso, caso uma controvérsia emerja entre os Estados membros do Tratado de Proibição, a CIJ poderá ser o terceiro responsável por solucionar o litígio nos termos em que lhe for atribuída normalmente competência segundo o Artigo 36 de seu Estatuto.

\section{Das Considerações SObre a República das IlHas Marshall.}

Estados, ao recorrer a um tribunal internacional, podem possuir interesses diversos daqueles formulados no

13 Tratado. Preâmbulo. Do original: "Reaffirming that there exists an obligation to pursue in good faith and bring to a conclusion negotiations leading to nuclear disarmament in all its aspects under strict and effective international control". pedido e causa de pedir perante um específico órgão jurisdicional internacional ${ }^{14}$. Ás vezes, o recurso a esses órgãos jurisdicionais ultrapassa a lide em questão. Estados podem utilizar uma corte internacional unicamente para expor uma teoria, para lapidar um regime jurídico, para testar o conteúdo desta ou determinada obrigação. Diversos são os estudos sobre as novas funções assumidas por cortes e tribunais internacionais ${ }^{15}$.

Quando uma causa é levada a um tribunal internacional, a atenção de diversos setores da sociedade internacional se volta àquela controvérsia. Quando se porta uma causa à "velha dama do direito internacional"16 _ órgão que detém, por uma longa série de motivos, certa proeminência em relação a seus competidores jurisdicionais — sabe-se que a atenção poderá ganhar ainda maior destaque.

O objetivo das República das Ilhas Marshall, em seu memorial, era claro e pontual em relação aos Estados demandados. Além da declaração da violação por parte de suas obrigações de negociação em boa-fé por parte dos Estados demandados, a República das Ilhas Marshall requeria que a Corte ordenasse os Estados demandados

a tomar todos os passos necessários ao cumprimento com suas obrigações relativas ao Artigo VI do Tratado de Não Proliferação de Armas Nucleares e relativas ao direito internacional costumeiro no período de um ano após o Julgamento, incluindo a persecução, por iniciativa própria se necessário,

14 A questão é interessante e criticamente explorada por BENVENISTI, Eyal; DOWNS, George W. "Prospects for the Increased Independence of International Tribunals", German Law Journal, Vol. 12, No. 5, 2011.

15 Para citar apenas dois exemplos significativos, ver ALTER, Karen J. The Multiple Roles of International Courts and Tribunals: Enforcement, Dispute Settlement, Constitutional and Administrative Review. In DUNOFF, Jeffrey L; POLLACK, Mark A. (orgs) Interdisciplinary perspectives on international law and international relations: the state of the art. Cambridge: Cambridge University Press, 2013. pp. 345-370 e BOGDNADY, Armin von; VENZKE, Ingo. In whose name?: a public law theory of international adjudication. Oxford: Oxford University Press, 2014.

16 Tudo parece indicar que essa expressão foi cunhada pelo professor Antônio Cassese, que intitulou seu célebre artigo como "The International Court of Justice: it is High Time to restyle the Respected Old Lady" (CASSESE, Antonio. The International Court of Justice: it is High Time to restyle the Respected Old Lady. In CASSESE, Antonio. Realizing Utopia: the future of international law. Oxford: Oxford University Press, 2012. pp.239-249). O estimulante ensaio do professor Cassese, bastante crítico à alguns estruturantes delineamentos e posicionamentos da CIJ, joga com a autoridade advinda da antiguidade do órgão jurisdicional e o papel a ela almejado no interior da comunidade internacional. 
de negociações em boa-fé focadas na conclusão de uma convenção sobre o desarmamento nuclear em todos os seus aspectos sob um controle internacional estrito e efetivo ${ }^{17}$.

O entendimento da maioria da Corte pela ausência de uma controvérsia impediu que as intentadas declarações fossem realizadas. Porém, ao se analisar as demais declarações da Corte, a título de obiter dicta, existem duas passagens em especial que parecem ser particularmente importantes para a República das Ilhas Marshall. A primeira ocorre no parágrafo 16 , em que a Corte recapitula, parcialmente, a história das Ilhas Marshall e o fato de que, sob o sistema de tutela das Nações Unidas, o arquipélago foi colocado sob a autoridade administrativa dos Estados Unidos, que conduziu ali testes nucleares. ${ }^{18}$ Embora seja fato notório, trata-se de adicional registro por órgão judiciário de um ato chancelado pelo sistema das Nações Unidas e de uma de suas principais potências. Além disso, ao abordar a questão da legitimidade de ação, no parágrafo 44, a CIJ, em seu julgamento, registra que

A Corte nota que as Ilhas Marshall, em virtude do sofrimento que o seu povo suportou pelo fato de ter sido utilizada como local para extensivos programas de testes nucleares, possui razões especiais para preocupar-se com o desarmamento nuclear ${ }^{19}$.

Tal declaração não pode ser retirada de seu con-

17 Memorial, p. 39 (Reino Unido), p. 36 (Índia), p. 24 (Paquistão). Do original: "In addition, The Republic of the Marshall Islands requests the Court to order the United Kingdom to take all steps necessary to comply with its obligations under Article VI of the Treaty on the Non-Proliferation of Nuclear Weapons and under customary international law within one year of the Judgment, including the pursuit, by initiation if necessary, of negotiations in good faith aimed at the conclusion of a convention on nuclear disarmament in ali its aspects under strict and effective international control". Por óbvio, em relação ao Paquistão e a Índia não se pedia a implementação do TNP.

18 Caso do Desarmamento Nuclear, nota 1 supra Reino Unido, para. 16: "By resolution 21 of 2 April 1947, the United Nations Security Council placed a group of Pacific Islands, including those making up the present-day Marshall Islands, under the trusteeship system established by the United Nations Charter, and designated the United States of America as the Administering Authority. From 1946 to 1958 , while under this trusteeship, the Marshall Islands was the location of repeated nuclear weapons testing. By resolution 683 of 22 December 1990, the Security Council terminated the Trusteeship Agreement concerning the Marshall Islands. By General Assembly resolution 46/3 of 17 September 1991, the Marshall Islands was admitted to membership in the United Nations."

19 Caso do Desarmamento Nuclear, nota 1 supra Reino Unido, para. 44. Do original: "The Court notes that the Marshall Islands, by virtue of the suffering which its people endured as a result of it being used as a site for extensive nuclear testing programs, has special reasons for concern about nuclear disarmament". texto. É verdade que a Corte fez esse reconhecimento logo antes de afirmar que as Ilhas Marshall deveriam ter provado a existência de uma controvérsia - o que a maioria dos juízes entendeu não ter logrado. Contudo, ainda que em forma de ponderação, trata-se de reconhecimento importante por pelo menos duas razões.

A primeira razão é o fato de o principal órgão judiciário da Organização das Nações Unidas reconhecer, expressamente, o sofrimento suportado pelo povo. Trata-se, como anteriormente salientado, de um alto reconhecimento não somente ao Estado, mas a população desse Estado, diretamente endereçada pelo frasear da Corte. Esse aspecto também foi explorado por juízes em suas opiniões individuais, em especial pelo juiz Cançado Trindade que, em diversas passagens de suas opiniões dissidentes, salientou os danos afligidos pela população em razão dos testes nucleares ${ }^{20}$. A segunda razão que indica a importância de tal declaração pela Corte é o reconhecimento da legitimidade das Ilhas Marshall na preocupação (ela possui "razões especiais", segundo a Corte) com o desarmamento nuclear. Poder-se-ia tentar vislumbrar essa iniciativa da Corte como uma espécie de reconhecimento histórico em relação a fatos não centrais à controvérsia, mas centrais à imagem pública do Estado. No entanto, dificilmente poder-se-ia sustentar que essa declaração da Corte poderia constituir satisfação à República das Ilhas Marshall pela controvérsia em si.

Num momento histórico em que negacionismos não são tão raros na ordem do dia do discurso político, a afirmação por parte de um tribunal internacional do sofrimento de uma determinada população pode ser considerada como digno de nota e apreço. Ademais, o reconhecimento por parte da Corte de tal fato é igualmente relevante ao se considerar que a história das Ilhas Marshall (e do sofrimento de seu povo) ganhou inquestionável publicidade em virtude do caso e do ativismo de seu agente ${ }^{21}$.

Por fim, sob o ponto de vista do direito de ação perante a Corte Internacional de Justiça, é interessante notar

20 Cançado, parágrafos 175, 176 e 177.

21 Falecido recentemente, Tony de Brum foi relembrado em obituário do New York Times (https://www.nytimes. com/2017/08/22/world/tony-de-brum-dead-climate-change-advocate.html) não apenas por defender as Ilhas Marshall na questão nuclear, mas igualmente pela questão do aquecimento global, outra ameaça constante para o desaparecimento das ilhas que compõem o Estado-Arquipélago. 
que, apesar do reconhecimento da Corte, a República das Ilhas Marshall não aparece no polo ativo da presente ação na qualidade de Estado diretamente afetado por um dano. O fundamento da ação baseia-se em obrigações de caráter erga omnes e, no específico caso do Reino Unido, parte do TNP, obrigações erga omnes partes. O objetivo da República das Ilhas Marshall não era a reparação por danos, mas sim o adimplemento da obrigação pactual e consuetudinária por parte dos Estados demandados. Contudo, como bem notado por observadores $^{22}$, a questão da legitimidade das Ilhas Marshall permaneceu inexplorada, uma vez que a Corte não adentrou o mérito.

\section{Dos DEBATES PROCESSUAIS}

O terceiro aspecto que atesta a relevância do caso do Desarmamento Nuclear é a quantidade de questões processuais que foram solevadas e discutidas pelos Estados litigantes perante a Corte. Nesta seção, não se poderá adentrar, profundamente, em cada um dos debates processuais entabulados pelas partes relativas às cinco objeções preliminares, mas será feita referência aos principais deles, quais sejam, a noção de existência de controvérsia, o debate sobre a necessidade de um terceiro Estado participando da lide, também alcunhado como a aplicação do princípio do Ouro Monetário e, por fim, a objeção do efeito útil do julgamento. O objetivo é, por meio de um tour d'horizon, demonstrar a importância dos debates ocorridos no Grande Salão de Justiça do Palácio da Paz e o fato de que as manifestações de alguns juízes em suas opiniões sobre a questão podem ser relevantes em futuros litígios. Obviamente, os pontos solevados tratavam-se de tentativas de esquivar-se da jurisdição da Corte. Contudo, eles revelaram uma dimensão processual inexplorada e que, ao menos nas opiniões individuais dos juízes, encontraram certo respaldo.

Como se sabe, o aumento de cortes e tribunais internacionais gerou o desenvolvimento de normas processuais relativas à condução das controvérsias perante essas instâncias jurisdicionais ${ }^{23}$. Normas regulando o

22 GRAY, nota 1 supra, p. 426.

23 Sobre a questão ver, BROWN, Chester. A common law of international adjudication. Oxford: Oxford University Press, 2007. SARVARIAN, Arman et al (orgs.) Procedural fairness in international courts and tribunals. Londres: British Institute of Interna- mero desenrolar das etapas processuais, normas relativas à jurisdição cautelar ${ }^{24}$, procedimentos incidentais relativos à jurisdição e admissibilidade até procedimentos específicos como a nomeação de peritos ${ }^{25}$ e a possibilidade de terceiros Estados intervirem no procedimento ${ }^{26}$ - uma característica não usual à lógica "privada" e “arbitral" do sistema judiciário internacional ${ }^{27}$. Não por acaso a Corte Internacional de Justiça ganhou proeminência ao guiar o procedimento perante outras cortes internacionais ${ }^{28}$.

A questão da existência de uma controvérsia e do debate da "ciência" sobre a pretensão do demandante encerrou o caso, mas os debates entre as partes foram além dessa questão. A Corte preferiu não responder aos argumentos levantados ao entender que bastava o argumento da controvérsia para que se encerrasse o litígio. Contudo, como justamente observou o juiz Gaja,

\begin{abstract}
esta abordagem pode ser entendida como a aplicação do princípio da economia judicial. Contudo, economia judicial pode também requerer que a Corte tome uma decisão em certas questões que foram levantadas pelo Estado demandado e que são prováveis de serem litigadas novamente em novos procedimentos pelas mesmas Partes, quando estes procedimentos são uma possibilidade distinta (CIJ, 2016, Declaração Juiz Gaja) ${ }^{29}$.
\end{abstract}

tional and Comparative Law, 2015. Do ponto de vista histórico do nascimento do debate, ver SERENI, Angelo Piero. Principi generali di diritto e processo internazionale. Milão: Giuffrè, 1955.

24 Sobre a questão ver PALCHETTI, Paolo. The Power of the International Court of Justice to Indicate Provisional Measures to Prevent the Aggravation of a Dispute, Leiden Journal of Internaiconal Law, Vol 21, 2008, pp. 623-642.

25 GAJA, Giorgio. Assessing Expert Evidence in the ICJ, The Law and Practice of International Courts and Tribunals, Vol. 15, 2017, pp. 409-418; LIMA, Lucas Carlos. O uso de experts em controvérsias ambientais perante a Corte Internacional de Justiça, Revista Brasileira de Direito Internacional, Vol. 13, 2016, pp.245-261 e o clássico WHITE, Gillian Mary. The use of experts by international tribunals. Syracuse: Syracuse University Press, 1965.

26 Sobre a questão ver BONAFÈ, Beatrice. La protezione degli interessi di Stati terzi davanti alla Corte internazionale di giustizia. Napoli: Editoriale Scientifica, 2014.

27 CANNIZZARO, Enzo. Diritto Internazionale. Torino: Giappichelli, 2012, p.358 e FORLATI, Serena. The International Court of Justice: an arbitral tribunal or a judicial body?. New York: Springer, 2014.

28 MAROTTI, Loris. The International Court of Justice Role in Influencing the Approach of other Courts on Fundamental Procedural Matters. In ARCARI, Maurizio; BALMOND, Louis. (orgs). Le dialogue des juridictions dans l'ordre juridique international : entre pluralisme et sécurité juridique. Napoli: Editoriale Scientifica, 2014, pp.7-27.

29 Caso do Desarmamento Nuclear, nota 1 supra Reino Unido, Declaração do Juiz Gaja, p. 1. Do original: "This approach may be viewed as an application of the principle of judicial economy. How- 
Pode-se, igualmente, solevar a hipótese de que as objeções levantadas não servem somente no caso das Ilhas Marshall desejar trazer novamente a controvérsia perante a Corte uma vez sanada a primeira objeção de inexistência de uma controvérsia (difícil sustentar que Reino Unido, Índia e Paquistão não estavam "cientes" da controvérsia após terem sido demandados perante a CIJ). Tais questões podem ser úteis em futuros casos relativos a outros Estrados. Talvez o princípio de economia judicial possa ser balanceado com outros princípios processuais como transparência e due process. Tal argumento parece ser ainda mais relevante se se considera que são questões procedimentais que estão em jogo, e a Corte é senhora de seu próprio regramento processual. É verdade que não existe nenhuma obrigação incidindo sobre a Corte de responder a todos os argumentos levantados pelas partes. Mas é igualmente verdade que Estados com situações procedimentais similares poderiam se beneficiar de posicionamentos da Corte sobre questões procedimentais idênticas ou similares.

O principal aspecto processual do caso do Desarmamento Nuclear é a questão da existência de uma controvérsia. No caso, a Corte acrescentou um elemento à clássica definição de controvérsia oferecida no caso $M a$ vrommatis e repetida significativamente ao longo de sua jurisprudência. Para a CIJ, o conceito de controvérsia era originalmente entendido como "um desacordo a respeito de um ponto de direito ou de fato, uma contradição, uma oposição de teses jurídicas ou de interesses" (CPJI, 1924, p.11) entre as partes. A Corte, baseando-se em sua recente jurisprudência, acrescentou que "uma dispute existe quando é demonstrado, com base em provas, que o demandado estava ciente ("aware"), ou não poderia não estar ciente ("unaware") que suas posições estavam 'positivamente contrastantes' à do demandante" (CIJ, 2016UK, para 41 $)^{30}$. Desse modo, ao entender que as Ilhas Marshall não haviam demonstrado que Reino Unido, Índia ou Paquistão estavam cientes da demanda de

ever, judicial economy may also require the Court to take a decision on certain issues that were raised by the respondent States and which are likely to have to be litigated again in new proceedings between the same Parties, when these proceedings are a distinct possibility". Na mesma linha ver, GRAY, nota 1 supra, 432.

30 Do original: "The evidence must show that the parties "hold clearly opposite views" with respect to the issue brought before the Court (see paragraph 37 above). As reflected in previous decisions of the Court in which the existence of a dispute was under consideration, a dispute exists when it is demonstrated, on the basis of the evidence, that the respondent was aware, or could not have been unaware, that its views were "positively opposed" by the applicant". negociação do desarmamento nuclear, a Corte concluiu que não existia uma verdadeira controvérsia. Por conseguinte, em não havendo uma controvérsia, o caso não prosseguiu para o mérito e foi encerrado.

O ponto da existência ou não de uma controvérsia efetivamente dividiu a Corte no interpretar de sua jurisprudência. Apenas para evidenciar dois exemplos, o juiz Crawford, em sua opinião dissidente, entendeu que "a Corte agora adota um requerimento de objetiva ciência, mas por nenhuma razão persuasiva. (...). Em nenhum momento a Corte [no passado] disse que a ciência era um requisito legal [para a existência de uma controvérsia]"31. Em igual sentido, o juiz Bennouna reforçou o fato de a Corte ter criado um "novo critério" e seus efeitos quando assevera que "ao criar (...) um novo critério para a existência de uma controvérsia, a maioria [da Corte] está seriamente comprometendo a abordagem da Corte no futuro sobre a questão da existência ou não de uma controvérsia". ${ }^{32}$ A forte divisão da Corte nesse sentido pode sugerir que, apesar de esta ter sido a opinião da maioria, não se trate de uma decisão que não possa ser revertida no futuro, a depender do contexto, dos juízes que compõem a Corte e dos especiais delineamentos da controvérsia. De todo modo, o artigo 59 do Estatuto impõe que "a decisão da Corte só será obrigatória para as partes litigantes e a respeito do caso em questão". Caso uma situação semelhante surja perante a Corte, os Estados litigantes terão uma boa consonância de opiniões dissidentes para sustentar suas pretensões jurídicas.

Ainda em conexão com a existência ou não da controvérsia, é interessante observar que a Corte se manifestou sobre um dos Artigos sobre Responsabilidade do Estado sobre Atos Ilícitos Internacionais (AREAII ou Artigos). Tal manifestação pode ser interpretada como um esclarecimento da Corte em relação ao projeto de artigos. Um dos argumentos do Reino Unido era embasado na natureza consuetudinária do Artigo 43 dos AREAII, que estabelece que "um Estado lesado que invoca a responsabilidade de outro Estado deverá notificá-lo da reclamação". Desse modo, segundo o Reino

31 Caso do Desarmamento Nuclear, nota 1 supra Reino Unido, Opinião Dissidente do Juiz Crawford, paras 4 e 5.

32 Caso do Desarmamento Nuclear, nota 1 supra Reino Unido, Opinião Dissidente do Juiz Bennouna, p. 6. Do original: "In putting forward, on that basis, a new criterion for the existence of a dispute, the majority is seriously compromising the approach of the Court in future to the question of whether a dispute exists" 
Unido, na ausência de uma notificação de reclamação imposta pela regra costumeira espelhada no Artigo 43, a controvérsia das Ilhas Marshall não poderia ser adjudicada. Porém, nesse ponto a CIJ rejeitou esse posicionamento do Reino Unido, esclarecendo que

\begin{abstract}
A Corte nota que os Comentários da Comissão de Direito Internacional especificam que os Artigos 'não se referem a questões de jurisdição de cortes e tribunais internacionais, ou em geral à condição para a admissibilidade de casos trazidos perante estas cortes ou tribunais' (...). A Corte rejeitou o entendimento de que negociações preliminares são necessárias quando ela for acionada com bases nas declarações feitas em relação ao Artigo 36, parágrafo 2, do Estatuto, a menos que estas declarações assim prevejam (CIJ, 2016UK, para. 45) ${ }^{33}$.
\end{abstract}

Tal observação é interessante por dois motivos. Primeiramente, por reforçar sua jurisprudência e indicar que uma notificação não é necessária para configurar o direito de ação - muito embora à luz da decisão da necessidade de "ciência" de uma controvérsia, esta possa ser bem-vinda. A segunda razão pela qual tal passagem demonstra-se importante é porque a CIJ parece se referir de maneira autoritativa aos comentários dos Artigos da Comissão. Tal fato parece contribuir à discussão sobre a autoridade dos produtos da Comissão de Direito Internacional como fontes consuetudinárias de direito internacional, mas igualmente aos comentários de tais produtos à interpretação dos próprios artigos ${ }^{34}$. E ainda, tal dictum pode ter como efeito a modificação de algumas declarações de jurisdição obrigatória do artigo 36. Pode-se conjecturar que Estados vejam-se interessados em modificar suas declarações de aceitação de jurisdição obrigatória incluindo o requisito de negociações preliminares para o acesso à Corte.

Além da questão da existência de uma controvérsia, pode-se vislumbrar, nas decisões de 2016, pelo menos

33 Do original: "However, the Court notes that the ILC's commentary specifies that the Articles "are not concerned with questions of the jurisdiction of international courts and tribunals, or in general with the conditions for the admissibility of cases brought before such courts or tribunals" (see ILC Commentary on the Draft Articles on the Responsibility of States for Internationally Wrongful Acts, Report of the International Law Commission, United Nations, doc. A/56/10, 2001, paragraph 1 of the Commentary on Article 44, pp. 120-121).Court has rejected the view that notice or prior negotiations are required where it has been seised on the basis of declarations made pursuant to Article 36, paragraph 2, of the Statute, unless one of those declarations so provides."

34 Sobre a questão, ver GAJA, Giorgio. Interpreting Articles Adopted by the International Law Commission. The British Yearbook of International Law, Vol. 85, 2014, pp.10-20. três argumentos procedimentais nos quais a Corte poderia ter se manifestado, mas não o fez: o argumento da incidência do princípio do Ouro Monetário, do efeito útil do julgamento e a incidência das reservas à cláusula de jurisdição obrigatória. Em relação a esses últimos, embora extremamente relevantes para a matéria de interpretação das reservas à jurisdição da declaração facultativa de jurisdição obrigatória do Art. 36 do Estatuto, são demasiadamente específicos às reservas individuais de cada um dos três Estados demandados.

No que se refere ao princípio do Ouro Monetário, também invocado como objeção preliminar pelos Estados demandantes, este encontrou reverberação na opinião individual de alguns juízes. É de se notar que diversas vezes esse princípio figurou nas linhas de defesa de Estados tentando esquivar-se da jurisdição da Corte. Segundo esse princípio, que no âmbito internacional se vê relacionado ao caso Monetary Gold Removed from Rome in $1943^{35}$, uma corte internacional não pode decidir uma questão jurídica que esteja relacionada a um Estado que não ofereceu seu consentimento ao tribu$\mathrm{na}^{36}$. Introduz-se, no âmbito do processo internacional, a noção de terceira parte indispensável à controvérsia, com o detalhe desse instituto estar associado ao consen-

35 CORTE INTERNACIONAL DE JUSTIÇA. Monetary Gold Removed from Rome in 1943 (Italy v. France, United Kingdom of Great Britain and Northern Ireland and United States of America). ICJ Reports 1954, p. 19. Sobre a questão,ver desenvolvimentos recentes em PALCHETTI, Paolo. Litigating Member State Responsibility: the Monetary Gold Principle of Absent Organizations. International Organizations Law Review, Vol. 12, 2015, pp. 468-483. THIENEL, Tobias. Third States and the Jurisdiction of the International Court of Justice: The Monetary Gold Principle. German Yearbook of International Law, Vol. 57, 2015, pp.321-352

36 Segundo a Corte, no caso em questão: "In order, therefore, to determine whether Italy is entitled to receive the gold, it is necessary to determine whether Albania has committed any international wrong against Italy, and whether she is under an obligation to pay compensation to her; and, if so, to determine also the amount of compensation. In order to decide such questions, it is necessary to determine whether the Albanian law of January qth, 1945, was contrary to international law. In the determination of these questions - questions which relate to the lawful or unlawful character of certain actions of Albania vis-à-vis Italy-only two States, Italy and Albania, are directly interested. To go into the merits of such questions would be to decide a dispute between Italy and Albania. The Court cannot decide such a dispute without the consent of Albania. But it is not contended by any Party that Albania has given her consent in this case either expressly or by implication. To adjudicate upon the international responsibility of Albania without her consent would run counter to a well-established principle of international law embodied in the Court's Statute, namely, that the Court can only exercise jurisdiction over a State with its consent." (CIJ, Monetary Gold Removed from Rome in 1943, nota 34 supra, p.32. 
timento dessa terceira parte. No caso Certain Phosphate Lands in Nauru (Nauru v. Australia) ${ }^{37}$, a Austrália invocou o mesmo princípio e o precedente do Ouro Monetário alegando que o Reino Unido e Nova Zelândia também deveriam estar na controvérsia, mas que não haviam oferecido seu consentimento. Todavia, naquela ocasião a Corte rejeitou tal objeção preliminar. Segundo a Corte, os interesses do Reino Unido e Nova Zelândia "não constitu[íam] o objeto da decisão" (CIJ, 1992 para 55).

No caso do Desarmamento Nuclear, o argumento utilizado pelos Estados demandados — invocando o princípio do caso do Ouro Monetário - baseava-se na impossibilidade de a CIJ decidir a questão relativa à obrigação de negociar trazida pelas Ilhas Marshall, uma vez que a violação da obrigação somente poderia ser verificada se todos os outros Estados portadores de armas nucleares tivessem manifestado seu consentimento à CIJ. Como observou o advogado de defesa do Reino Unido, "uma determinação pela Corte de que o Reino Unido está violando suas obrigações de negociar por conta de sua conduta não pode ser restrita somente ao Reino Unido" (CIJ, 2016, CR 2016/3 p. 57)..$^{38}$ Por sua vez, as Ilhas Marshall, baseando-se nos mesmos julgados invocados pelo Reino Unido, alegava que a identificação do comportamento violador do Reino Unido era independente dos outros Estados, uma vez que estes não constituíam o objeto da controvérsia. Nas palavras do advogado de defesa das Ilhas Marshall, "esta Corte esclareceu que o princípio do Ouro Monetário se aplica apenas onde a determinação da responsabilidade de um terceiro Estado é um pré-requisito para a determinação da responsabilidade do Estado demandado"39 (CIJ, 2016, CR 2016/5, p. 38). A questão a ser verificada, portanto, consistia em saber se a responsabilidade dos outros Estados detentores de armas nucleares era um pré-requisito para a determinação da responsabilidade dos Estados demandados. Por outro lado, poder-se-ia, igualmente, aduzir a tese de que a presença de pelo menos três Estados demandados poderia constituir suficiente preenchimento de tal requisito.

37 CORTE INTERNACIONAL DE JUSTIÇA, Certain Phosphate Lands in Nauru (Nauru v. Australia). ICJ Reports 1992.

38 Do original: "Consequently a determination by the Court that the United Kingdom is in breach of its obligations to negotiate by reason of this conduct cannot be confined to the United Kingdom alone".

39 Do original: "This Court has clarified that the Monetary Gold principle only applies where the determination of the responsibility of a third State is a prerequisite for the determination of the responsibility of the respondent State"
A Corte não se manifestou sobre a aplicação do princípio do Ouro Monetário no caso do Desarmamento Nuclear. Contudo, alguns juízes referiram-se à objeção em suas opiniões individuais. Tal fato pode sugerir que tenha sido alvo de particular debate dos juízes no momento da deliberação. Enquanto os juízes Tomka ${ }^{40}, X_{u} e^{41}$ e Bhandari ${ }^{42}$ mostraram sua inclinação para a aplicação do princípio no caso em questão, o juiz Crawford adotou uma posição mais moderada - e ligeiramente favorável à não aplicação do princípio em via preliminar — entendendo ser esta uma questão para o mérito ${ }^{43}$. O juiz Cançado Trindade, por sua vez, dedicou parte de sua opinião à "impertinência" do princípio, associando-o a distorções geradas pela "obsessão com o estrito paradigma interestatal" ${ }^{44}$. Caso o princípio seja invocado novamente no futuro, talvez não seja de se surpreender que as opiniões oferecidas pelos juízes no presente caso venham a ser invocadas para integrar a linha defensiva dos Estados litigantes. Assim, ainda que não tenha sido objeto direto da decisão da Corte, as opiniões dissidentes em si demonstram a relevância do caso perante a CIJ.

Por fim, nota-se que os três Estados demandados levantaram como objeção preliminar o fato de que "a Corte deveria declinar o exercício de sua jurisdição porque uma decisão no mérito seria privada de uma consequência prática" ${ }^{\prime 5}$. A tese sustentada foi basicamente embasada em dois anteriores julgamentos da Corte ${ }^{46}$, nos quais a Corte afirmou que "existem limitações inerentes ao exercício da função judicial que a Corte, como uma corte de justiça, nunca pode ignorar. (...) É a própria Corte, e não as partes, que devem ser as guardiãs da integridade judicial da Corte". ${ }^{47}$ Em duas ocasiões, a Corte utilizara um argumento similar para afastar sua jurisdição vez que se tratavam de situações irreversíveis. No presente caso, de acordo com os Estados demandados, um julgamento que declarasse a violação da obrigação de negociar seria "incapaz de qualquer significativa

\footnotetext{
$40 \quad$ Tomka Para 39

41 Xue, para 9.

42 Bhandari, Paras 18-20.

43 Crawford, para. 33.

44 Cançado Trindade, paras 128-131.

45 Caso do Desarmamento Nuclear, nota 1 supra Reino Unido, para 23; India, para 22; Paquistão, para 22.

46 Northern Cameroons (Cameroon v. United Kingdom), Preliminary Objections, Judgment, I.C.J. Reports 1963, p. 15; Nuclear Tests (Australia v. France), Judgment, I.C.J. Reports 1974, p. 253.

47 Northern Cameroons (Cameroon v. United Kingdom), Preliminary Objections, Judgment, I.C.J. Reports 1963, p. 29.
} 
e efetiva aplicação" ${ }^{48}$, sobretudo porque dependente de terceiros Estados. Nota-se aqui uma sobreposição das objeções de "efeito útil" e do Ouro Monetário. A objeção não reverberou nas opiniões dos juízes, que pouco discorreram sobre o potencial efeito útil e a integridade judicial da Corte nesse caso. Apenas o juiz Bandhari mencionou que essa questão deveria ter sido decidida ${ }^{49}$. Embora seja inconclusivo elaborar hipóteses com base no silêncio da Corte e da maioria dos juízes, pode-se questionar se, na atualidade, o argumento de "efeito útil” de um julgamento relacionando-se à "integridade judicial" de um tribunal internacional seja ainda eloquente.

A decisão preliminar da Corte Internacional de Justiça no caso do Desarmamento Nuclear foi uma decisão de natureza processual. Sem tocar o mérito, arguiu-se e verificou-se os requisitos à jurisdição e admissibilidade da demanda. Independentemente de como possa ser interpretado o julgamento, os três argumentos procedimentais aqui cotejados confirmam a tese da relevância do caso do Desarmamento Nuclear perante a Corte Internacional de Justiça.

\section{Considerações finais SOBRE A ReleVÂnCIA DO CASO}

Juntamente às opiniões consultivas dos casos South West Africa (1966) e Legalidade do Uso e a Amaça de Armas Nucleares (1966), o caso do Desarmamento Nuclear repousa no rol dos casos em que a Corte beirou as fronteiras entre o político e o jurídico e dividiu-se. Os juízes dissidentes são eloquentes como poucas vezes foram juízes da CIJ. Tais fatos, e os três aspectos estudados neste trabalho, confirmam a relevância do caso para o direito internacional.

Não se pode deixar de observar que a decisão da Corte Internacional de Justiça, no caso do Desarmamento Nuclear, também confirma a hipótese de que tribunais e cortes internacionais desempenham papéis que ultrapassam o limite da mera solução de dissidências jurídicas. Tratam-se, também, de fóruns para o avançar de posições e argumentos jurídicos (por vezes igualmente e eminentemente políticos) que vão além da controvérsia

48 CR 2016/3, p. 30

49 Bhandari, para 24. em vigor. Desnecessário rememorar que os impactos políticos dessas decisões transpõem os jardins do Palácio da Paz.

Talvez possa-se conjecturar que a República das Ilhas Marshall, ao trazer um caso desse porte perante a Corte da Haia, cogitasse o possível trágico deslinde de sua tentativa de indicar a violação das normas de negociação do desarmamento nuclear pelos Estados portadores dessa espécie de armamento. Por fim, um desfecho como aquele encontrado nos três julgamentos de 2016, fruto de uma Corte extremamente dividida e com um casting vote do presidente, talvez possa ser considerado como o melhor dentre os piores resultados.

Em sua plaidoirie contra a Índia, o advogado das Ilhas Marshall, professor Luigi Condorelli, relembrou um antigo ditado italiano para apontar as inconsistências entre prática e discurso: "tra il dire e il fare c'è in mezzo il mare". Numa tradução bruta, poder-se-ia reproduzi-lo como "entre aquilo que se prega e aquilo que se faz, existe um mar de distância". Num contexto de intenso debate sobre armas nucleares, a atitude das Ilhas Marshall de atravessar tal mar e trazer à Corte Internacional de Justiça os Estados detentores de armas nucleares para apontar sua violação figura como uma iniciativa bastante conspícua e também distante do discurso de chancelarias.

\section{ReferênCIAS}

ALTER, Karen J. The Multiple Roles of International Courts and Tribunals: Enforcement, Dispute Settlement, Constitutional and Administrative Review. In DUNOFF, Jeffrey L; POLLACK, Mark A. (orgs) Interdisciplinary perspectives on international law and international relations: the state of the art. Cambridge: Cambridge University Press, 2013. pp. 345-370.

ANGHIE, Anthony. "Politic, Cautious, and the meticulous: an introduction to the symposium on the Marshall Islands case" AJIL Unbound, Vol. 111, pp. 62-67, 2017.

BENVENISTI, Eyal; DOWNS, George W. "Prospects for the Increased Independence of International Tribunals", German Law Journal, Vol. 12, No. 5, 2011.

BIANCHI, Andrea. "Choice and (the awareness of) its consequences: the ICJ's "structural bias" strikes again in the Marshall Islands case" AJIL Unbound, Vol. 111, pp. 81-87, 2017. 
BOGDNADY, Armin von; VENZKE, Ingo. In whose name?: a public law theory of international adjudication. Oxford: Oxford University Press, 2014.

BONAFÈ, Beatrice Ilaria. "La Cour internationale de Justice et la notion de différent" Ordine internazionale e diritti umani, Vol. 5, pp. 924-933, 2016.

BONAFÈ, Beatrice Ilaria. "La Cour internationale de Justice et la notion de différent" Ordine internazionale e diritti umani, Vol. 5, pp. 924-933, 2016.

BONAFÈ, Beatrice. La protezione degli interessi di Stati terzi davanti alla Corte internazionale di giustizia. Napoli: Editoriale Scientifica, 2014

BROWN, Chester. A common law of international adjudication. Oxford: Oxford University Press, 2007.

CANÇADO TRINDADE, Antônio Augusto. The Universal obligation of nuclear disarmament. Brasília: Fundação Alexandre de Gusmão.

CANNIZZARO, Enzo. Diritto Internazionale. Torino: Giappichelli, 2012.

CORTE INTERNACIONAL DE JUSTIÇA, Certain Phosphate Lands in Nauru (Nauru v. Australia). ICJ Reports 1992.

CORTE INTERNACIONAL DE JUSTIÇA. Legality of the Threat or Use of Nuclear Weapons. Opinião Consultiva. ICJ Reports 1996. p. 226.

CORTE INTERNACIONAL DE JUSTIÇA. Legality of the Use by a State of Nuclear Weapons in Armed Conflict. Opinião Consultiva. ICj Reports 1996. p. 66.

CORTE INTERNACIONAL DE JUSTIÇA. Monetary Gold Removed from Rome in 1943 (Italy v. France, United Kingdom of Great Britain and Northern Ireland and United States of America). ICJ Reports 1954, p. 19.

CORTE INTERNACIONAL DE JUSTIÇA. Nuclear Testes (New Zealand v. France). ICJ Reports 1974. p. 457.

CORTE INTERNACIONAL DE JUSTIÇA. Nuclear Tests (Australia v. France). ICJ Reports 1974. p. 253.

Corte Permanente de Justiça Internacional Affaire des Concessions Mavrommatis en Palestine, CPJI, 1924, p. 11

D'ASPREMONT, Jean. The Control Over Knowledge by International Courts and Arbitral Tribunals. In SCHULTZ, Thomas; ORTINO, Federico. (orgs) Ox- ford Handbook of International Arbitration. Oxford: Oxford University Press. (No prelo).

FORLATI, Serena. The International Court of Justice: an arbitral tribunal or a judicial body? New York: Springer, 2014.

GAJA, Giorgio. Assessing Expert Evidence in the ICJ, The Law and Practice of International Courts and Tribunals, Vol. 15, 2017, pp. 409-418.

GAJA, Giorgio. Interpreting Articles Adopted by the International Law Commission. The British Yearbook of International Law, Vol. 85, 2014, pp.10-20.

GALINDO, George Rodrigo Bandeira. "On form, substance and equality between States” AJIL Unbound, Vol. 111, pp. 75-80.

GRAY, Christine. "The 2016 Activity of the International Court of Justice", American Journal of International Law, Vol. 111, pp. 415-436, 2017

KRISCH, Nico. "Capitulation in The Hague: The Marshall Islands Cases”, Post no EJIL: Talk!, 10 de Outubro de 2016. Disponível em < https://www.ejiltalk. org/capitulation-in-the-hague-the-marshall-islands-cases $/>$

LIMA, Lucas Carlos. O uso de experts em controvérsias ambientais perante a Corte Internacional de Justiça, Revista Brasileira de Direito Internacional, Vol. 13, 2016, pp.245-261.

MAROT'TI, Loris. The International Court of Justice Role in Influencing the Approach of other Courts on Fundamental Procedural Matters. In ARCARI, Maurizio; BALMOND, Louis. (orgs). Le dialogue des juridictions dans l'ordre juridique international : entre pluralisme et sécurité juridique. Napoli: Editoriale Scientifica, 2014, pp.7-27.

PALCHETTI, Paolo. Litigating Member State Responsibility: the Monetary Gold Principle of Absent Organizations. International Organizations Law Review, Vol. 12, 2015, pp. 468-483.

PALCHETTI, Paolo. The Power of the International Court of Justice to Indicate Provisional Measures to Prevent the Aggravation of a Dispute, Leiden Journal of Internaiconal Law, Vol 21, 2008, pp. 623-642.

RANGANATHAN, Surabhi. "Nuclear Weapons and the Court" AJIL Unbound, Vol. 111, pp. 88-95, 2017. SARVARIAN, Arman et al (orgs.) Procedural fairness 
in international courts and tribunals. Londres: British Institute of International and Comparative Law, 2015.

SERENI, Angelo Piero. Principi generali di diritto e processo internazionale. Milão: Giuffrè, 1955.

STOPPIONI, Edoardo. "The ICJ Decisions In The Marshall Islands Cases Or The Unintended Consequences Of "Awareness", post no SIDIBlog, 24 de novembro de 2016. Disponível em http://www.sidiblog. org/2016/11/24/the-icj-decisions-in-the-marshallislands-cases-or-the-unintended-consequences-of-awareness/).

TAMS, Christian J. "World Courts as Guardians of Peace”, Global Cooperation Research Paper 15 (2016);
THIENEL, Tobias. Third States and the Jurisdiction of the International Court of Justice: The Monetary Gold Principle. German Yearbook of International Law, Vol. 57, 2015, pp.321-352.

TOMKA, Peter; PROULX, Vincent J., The Evidentiary Practice of the World Court in SAINZ-BORGO, JC. (org) Liber Amicorum Gudmundur Eiriksson. Leiden: University for Peace Press, 2016.

VENZKE, Ingo."Public interests in the International Court of Justice - a comparison between Nuclear Arms Race (2016) and South West Africa (1966)" AJIL Unbound, Vol. 111, pp.68-74.

WHITE, Gillian Mary. The use of experts by international tribunals. Syracuse: Syracuse University Press, 1965. 
Para publicar na Revista de Direito Internacional, acesse o endereço eletrônico www.rdi.uniceub.br ou www.brazilianjournal.org.

Observe as normas de publicação, para facilitar e agilizar o trabalho de edição. 